\title{
Efeito do Sistema Cantareira sobre o regime de vazões na bacia do rio Piracicaba
}

\author{
Effect of the Cantareira System on the flow regime in Piracicaba River basin
}

\author{
Aline Frederice ${ }^{1}$ e João Luiz Boccia Brandão ${ }^{1}$ \\ ${ }^{1}$ Universidade de São Paulo, São Carlos, SP, Brasil \\ E-mails: alinefrederice@hotmail.com (AF),jlbb@sc.usp.br (JLBB)
}

Recebido: Setembro 26, 2015 - Revisado: Maio 09, 2016 - Aceito: Agosto 09, 2016

\begin{abstract}
RESUMO
A operação de grandes reservatórios pode alterar toda a dinâmica fluvial natural de um curso d'água, sendo necessária uma melhor compreensão das influências destas interferências em busca de um gerenciamento adequado, minimizando impactos negativos. Diante disto, este trabalho buscou identificar as alterações ocorridas no regime de vazões dos principais rios da bacia do rio Piracicaba, principalmente em decorrência da implantação dos reservatórios do Sistema Cantareira. As análises foram feitas com base nas séries de vazões médias diárias de quatro postos fluviométricos localizados nos rios Atibaia, Jaguari, Piracicaba, os quais tem seu regime de vazões influenciados pela operação dos reservatórios do Sistema Cantareira, e no rio Camanducaia, que encontra-se na mesma bacia hidrográfica e não sofre influência desse sistema, para efeito de comparação. Foi utilizado o software IHA (Indicators of Hydrologic Alteration), que calcula alterações em 33 parâmetros hidrológicos relevantes ecologicamente, que caracterizam a magnitude, o tempo, a frequência, a duração e a taxa de flutuações das vazões. Foi constatado que, a partir das décadas de 1970 e 1980, para os rios sob influência do Sistema Cantareira, no geral, houve uma diminuição nas vazões médias, de aproximadamente $24 \%$ no rio Atibaia, $50 \%$ no rio Jaguari e $14 \%$ no rio Piracicaba, sendo que o decréscimo das vazões ocorreu principalmente na estação seca (abril a setembro), além da redução no valor da mediana das vazões mínimas anuais de 7 dias consecutivos em $25 \%$, $56 \%$ e 15\%, respectivamente. Também foi constatado diminuição na duração das vazões mais altas. As mudanças mais significativas ocorreram no rio Jaguari, seguido pelo rio Atibaia e foram menos significativas no rio Piracicaba, o qual se encontra mais distante dos reservatórios. Já para o rio Camanducaia, após a década de 1970, não houve mudança no valor da mediana das vazões mínimas anuais de 7 dias consecutivos e constatou-se, no geral, um aumento nas vazões médias de aproximadamente $21 \%$, assim como o aumento na frequência de ocorrência das vazões máximas. Porém, as mudanças não foram tão significativas como nos demais rios.
\end{abstract}

Palavras-chave: Bacias PCJ; Sistema Cantareira; Vazão ecológica; Método IHA.

\begin{abstract}
The large reservoirs operation can change all the natural fluvial dynamics of a river, requiring a better understanding about the influences of these interferences to an appropriate management, minimizing negative impacts. Faced with this, the aim in this paper was to identify the alterations in the flow regime of the main rivers of Piracicaba River basin, mainly due to the implementation of Cantareira System reservoirs. The analyzes were based on the average daily flow series from four fluviometric stations in the rivers Atibaia and Jaguari and Piracicaba (influenced by Cantareira System) and Camanducaia (in the same basin but without influence from Cantareira System), for comparison, using the IHA (Indicators of Hydrologic Alteration) software, which calculates the hydrological alteration factors of the 33 hydrological parameters ecologically relevant, that characterizes the magnitude, timing, frequency, duration and rate of flow change. For the rivers influenced by Cantareira System was observed that from the $1970 \mathrm{~s}$ and 1980s, overall, there was a decrease in the mean flow, approximately $24 \%$ in Atibaia River, $50 \%$ in Jaguari River, and $14 \%$ in Piracicaba River, where in the decrease in the flows was mainly in the dry season (April to September), besides a decrease in the median of the annual seven days minimum flows by $25 \%$ and $56 \%$ and $15 \%$, respectively. There also an increase in the frequency and duration of the lower flows and a decrease in the duration of high flows. The most significant changes occurred in Jaguari River, followed by the Atibaia River and were less significant in the Piracicaba River, which is the farthest from the reservoirs.
\end{abstract}


For the Camanducaia River, after the 1970s, there was no change in the median of the annual seven days minimum flows and it was observed, overall, an increase in the mean flow by $21 \%$, as well as an increase in the frequency of the maximum flows. However, the changes were not as significant as in the others rivers.

Keywords: PCJ basins; Cantareira System; Environmental flow; Method IHA.

\section{INTRODUÇÃO}

Nas últimas décadas, foi consolidado o conceito de que a qualidade ambiental de um rio e dos ecossistemas associados é fortemente dependente do regime hidrológico como um todo, incluindo a magnitude das vazões mínimas e máximas, o tempo de duração das estiagens, a frequência das cheias, a época de ocorrência dos eventos de cheias e estiagens, entre outros (COLLISCHONN et al., 2005; RICHTER et al., 1996, 1997; MATHEWS; RICHTER, 2007).

Os reservatórios construídos em um curso d'água causam mudanças na dinâmica fluvial como a alteração no regime de vazões do rio. Conforme a atual legislação brasileira de recursos hídricos, os reservatórios estão condicionados a manterem apenas uma vazão mínima remanescente para jusante (denominada também de vazão ecológica), sendo esta calculada por métodos estatísticos.

Porém, Collischonn et al. (2005) afirmam que critérios de definição de vazões remanescentes (ou ecológicas), utilizados para a gestão de recursos hídricos, devem contemplar outros períodos que caracterizam o regime hidrológico, não só o período de vazões mínimas em época de estiagem.

Mathews e Richter (2007) também ressaltam que é importante caracterizar a variação natural das vazões de um curso d'água, em que as espécies nativas e os ecossistemas se adaptaram, comparando com as condições atuais ou simuladas para o futuro, podendo assim concentrar esforços para a preservação de vazões e atividades de restauração, fornecer orientação para pesquisa e monitoramento ecológico e identificar ações prioritárias de manejo.

Nesse contexto, este trabalho propõe uma análise do regime de vazões dos principais rios da bacia do rio Piracicaba, a qual é considerada de extrema importância para o Estado de São Paulo, visto que é responsável pelo abastecimento da região metropolitana de Campinas e grande parte da região metropolitana de São Paulo (RMSP), tendo sido implantado em suas cabeceiras os reservatórios do Sistema Cantareira, com capacidade de regularização e reversão de $31 \mathrm{~m}^{3} / \mathrm{s}$ de água dessa bacia para a bacia do Alto Tietê. Segundo Moraes et al. (1997) e Groppo et al. (2001) esses reservatórios causaram impactos significativos nas vazões dos rios a jusante.

\section{METODOLOGIA}

\section{Área de estudo}

A área de estudo é a bacia do rio Piracicaba (Figura 1), afluente na margem direita do rio Tietê, que, segundo o Plano das Bacias PCJ (COBRAPE, 2011), possui área de drenagem de $12.568,72 \mathrm{~km}^{2}$, estando $11.402,84 \mathrm{~km}^{2}(90,7 \%)$ inseridos no estado de São Paulo e 1.165,88 km² (9,3\%) no estado de Minas Gerais.
Essa bacia, juntamente com as bacias dos rios Capivari e Jundiaí, integra as bacias PCJ, cuja parte paulista constitui a Unidade de Gerenciamento de Recursos Hídricos número 5 do estado de São Paulo (UGRHI 5), sendo 82\% do território dessa UGRHI correspondente à bacia do rio Piracicaba.

É considerada uma bacia complexa e de extrema importância para o estado de São Paulo, visto que a UGRHI 5 é o segundo pólo econômico do estado, abrangendo a Região Metropolitana de Campinas, e importante centro industrial, concentrando as maiores demandas de água para abastecimento à jusante do Sistema Cantareira.

Esse sistema, que é um dos maiores sistemas de produção de água do mundo, foi implantado em duas etapas, sendo que a primeira delas foi constituída pela construção das barragens Paiva Castro no rio Juqueri (Bacia do Alto Tietê - regularização de $2 \mathrm{~m}^{3} / \mathrm{s}$ ), Cachoeira e Atibainha (Bacia do rio Piracicaba - regularização de $9 \mathrm{~m}^{3} / \mathrm{s}$ ), com início da operação desses reservatórios em 1973, 1974 e 1975, respectivamente, fornecendo uma vazão de $11 \mathrm{~m}^{3} / \mathrm{s}$ para a RMSP. A segunda etapa iniciou-se na década de 70, compreendendo a construção das barragens dos rios Jaguari e Jacareí (Bacia do Rio Piracicaba - regularização de $22 \mathrm{~m}^{3} / \mathrm{s}$ ), com início da operação em 1982, conferindo ao sistema a capacidade total de 33 m³/s (WHATELY; CUNHA, 2007).

Para a bacia do rio Piracicaba, são liberadas a jusante desses reservatórios, pelo sistema equivalente, cerca de $5 \mathrm{~m}^{3} / \mathrm{s}$, podendo essas vazões serem variáveis, conforme descrito pela Resolução Conjunta ANA/DAEE n ${ }^{\circ} 428 / 04$, com base na Nota Técnica Conjunta ANA/DAEE (ANA; DAEE, 2004).

Segundo o Plano das Bacias PCJ (COBRAPE, 2011), de modo geral, o clima da região é do tipo quente, temperado e chuvoso, com período chuvoso entre os meses de outubro e abril. Os índices de precipitação pluviométrica anuais variam, em média, entre 1.200 e $1.800 \mathrm{~mm}$.

De acordo com o mapa de uso e cobertura do solo elaborado por IRRIGART (2004), referente ao ano de 2003, a área de cobertura do solo predominante da bacia do rio Piracicaba é a pastagem (40,8\%), seguida pela agricultura $(36,8 \%)$, silvicultura e floresta $(15,1 \%)$, área urbana $(5,6 \%)$ e água $(1,7 \%)$.

\section{Base de dados}

Para este trabalho foram utilizados os dados das séries históricas de vazões médias diárias de quatro postos fluviométricos (Tabela 1) localizados na bacia do rio Piracicaba (Figura 1), fornecidos pelo Departamento de Água e Energia Elétrica (DAEE).

Conforme ilustrado na Figura 1, os reservatórios do Sistema Cantareira ficam localizados a montante dos postos fluviométricos selecionados nos rios Jaguari, Atibaia e Piracicaba. A soma das 


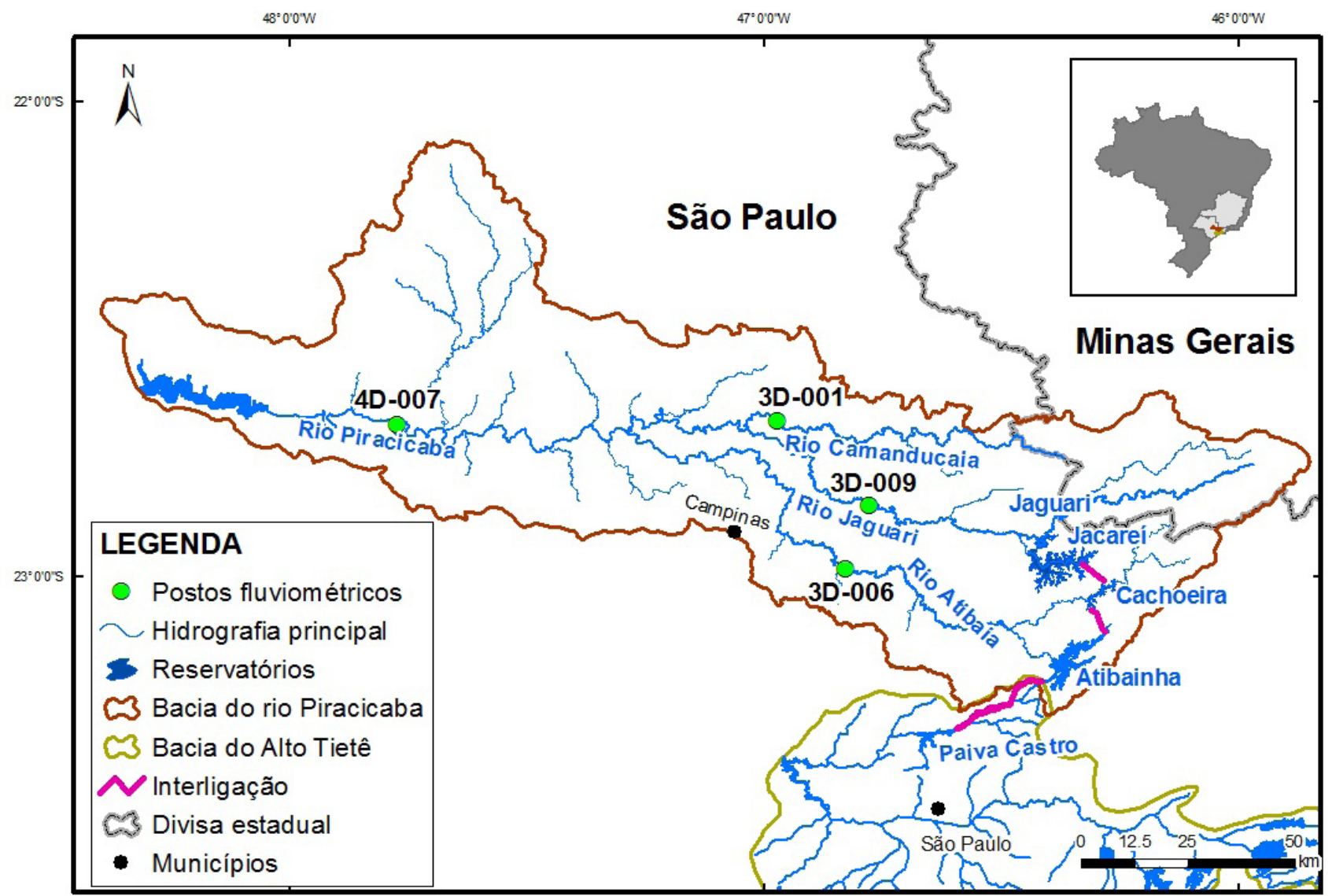

Figura 1. Localização dos postos fluviométricos e dos reservatórios do Sistema Cantareira.

Tabela 1. Postos fluviométricos.

\begin{tabular}{cccccc}
\hline Código & Nome do Posto & Município & Rio & $\begin{array}{c}\mathbf{A}_{\mathbf{d}}^{*} \\
\mathbf{( k m}^{\mathbf{2}} \mathbf{)}\end{array}$ & Período de dados \\
\hline 3D-001 & Fazenda da Barra & Jaguariúna & Camanducaia & 928 & $1944-2012$ \\
3D-006 & Bairro da Ponte & Itatiba & Atibaia & 1.920 & $1930-2012$ \\
3D-009 & Buenópolis & Morungaba & Jaguari & 1.950 & $1931-2012$ \\
4D-007 & Artemis & Piracicaba & Piracicaba & 10.918 & $1944-2012$ \\
\hline
\end{tabular}

$\mathrm{A}_{\mathrm{d}}^{*}$ : Área de drenagem.

áreas de drenagem dos reservatórios Jaguari e Jacareí corresponde a $1.252 \mathrm{~km}^{2}$ e dos reservatórios Cachoeira e Atibainha a $715 \mathrm{~km}^{2}$.

Os períodos indicados na Tabela 1 correspondem aos anos hidrológicos, sendo que os dados foram completados, através da correlação com outros postos, conforme descrito por Frederice (2014), para o preenchimento de algumas falhas existentes nos registros.

\section{Indicadores de alterações hidrológicas}

As análises de alterações hidrológicas dos rios Atibaia, Jaguari, Piracicaba e Camanducaia foram feitas através do software IHA (TNC, 2009), por meio da comparação entre dois períodos da série de vazões, denominados pré e pós-impacto.

Para a determinação do "ano do impacto" foi aplicado às séries de vazões o teste de hipótese não paramétrico de Pettitt
(Pettitt, 1979), por meio do programa XLSTAT (ADDINSOFT, 2014), uma vez que esse método identifica a data de ruptura da homogeneidade da série.

Para os rios influenciados pelo Sistema Cantareira foi possível verificar a hipótese de que essa ruptura seria próxima ao início da operação dos reservatórios, já que não houve um ano específico para início das operações, sendo o sistema implantado ao longo dos anos. E, para o rio Camanducaia, onde não foi identificada substancial interferência antrópica, foi aplicado também o teste de Pettitt para verificar se houve ruptura da homogeneidade da série, ocasionada possivelmente pelo aumento das chuvas na bacia, verificado por Moraes et al. (1997) e Groppo et al. (2001), e realizadas as análises entre dois períodos, através do método IHA, para efeito de comparação com os demais rios.

Assim, foram traçadas as curvas de permanência das vazões de cada posto e determinados os 33 parâmetros hidrológicos do 
método dos indicadores de alterações hidrológicas (IHA), definidos por TNC (2009) conforme Tabela 2. Estes parâmetros caracterizam a magnitude, o tempo, a frequência, a duração e a taxa de flutuações das vazões. Destaca-se neste trabalho o parâmetro "vazão mínima anual de 7 dias", a qual associada ao período de retorno de 10 anos é utilizada nesses rios como vazão de referência para a outorga.
Através do software IHA foi quantificado o grau de alteração hidrológica do período pós-impacto, por meio da análise não paramétrica dos dados. Para essa quantificação são definidas três categorias, chamadas de categorias RVA (Range of Variability Approach), as quais caracterizam faixas de variabilidade dos parâmetros naturais. Essas categorias são definidas através dos percentuais dos valores

Tabela 2. Parâmetros IHA e suas influências nos ecossistemas.

\begin{tabular}{c|c}
\hline $\begin{array}{c}\text { Grupo dos parâmetros } \\
\text { IHA }\end{array}$ & Parâmetros hidrológico \\
\hline
\end{tabular}

1. Magnitude das condições mensais de vazões (12 parâmetros) -mediana das vazões mensais, correspondendo à mediana dos valores das vazões diárias de cada mês.

\section{Influências no ecossistema}

- Habitat disponível para os organismos aquáticos

- Umidade do solo disponível para as plantas

- Disponibilidade e confiabilidade do fornecimento de água para animais terrestres

- Acesso por predadores aos locais de nidificação

- Influências na temperatura, níveis de oxigênio e fotossíntese na coluna de água

- Balanço de organismos competitivos, ruderais e estresse tolerantes

- Criação de locais para a colonização de plantas

- Estruturação dos ecossistemas aquáticos por fatores abióticos versus fatores bióticos

-vazões mínimas e máximas anuais de 1, 3, 7, 30

2. Magnitude e duração das condições extremas de vazão (12 parâmetros) e 90 dias consecutivos, sendo as vazões de 3 , 7, 30 e 90 dias calculadas com base na média móvel das vazões dentro do ano hidrológico; intermitência do rio; -índice de fluxo de base, calculado através da razão entre a vazão mínima anual de 7 dias e a média anual geral das vazões. - número de dias de vazão zero, para se determinar a

- Estruturação morfológica do canal do rio e das condições físicas de habitat

- Umidade do solo estressante para plantas

- Desidratação em animais

- Estresse anaeróbico em plantas

- Volume de trocas de nutrientes entre rio e planícies aluviais

- Duração de condições estressantes como baixo oxigênio e produtos químicos concentrados em ambientes aquáticos

- Distribuição de comunidades de plantas em lagos, lagoas e várzeas

- Duração de vazões elevadas para eliminação de resíduos e aeração de leitos de desova em canais de sedimentos

- Compatibilidade com os ciclos de vida dos organismos

- Previsibilidade/evitabilidade de estresse para os organismos

- Acesso a habitats especiais durante a reprodução ou para evitar a predação

- Indicação de desova de peixes migradores

- Evolução das estratégias de história de vida e mecanismos comportamentais

- Frequência e magnitude do estresse de umidade do solo para as plantas

- Frequência e duração do estresse anaeróbio para as plantas

-número de baixo e alto pulso que ocorrem no ano, sendo que a vazão de um determinado dia é considerada como um pulso alto se for maior que o $75^{\circ}$ percentil dos dados do período definido como pré-impacto e como pulso baixo se for menor do que o $25^{\circ}$ percentil; -duração de baixo e alto pulso, referente à mediana das durações de cada tipo de pulso no ano.

- Disponibilidade de habitats de várzea para os organismos aquáticos

- Troca de nutrientes e matéria orgânica entre o rio e a planície de inundação

- Disponibilidade mineral do solo

- Acesso de aves aquáticas a locais para alimentação, repouso e reprodução
4. Frequência e duração dos pulsos altos e baixos (4 parâmetros)

- Influências no transporte de sedimentos, texturas do canal de sedimentos e duração da perturbação do substrato (altos pulsos)

-taxas de ascensão e recessão da vaz̃ão $\left(\mathrm{m}^{3} / \mathrm{s} / \mathrm{dia}\right)$, que correspondem à mediana dos valores de cada

5. Taxa e frequência das mudanças de vazões $(3$ parâmetros) tipo de mudança (positiva e negativa) na vazão entre um dia e o outro;

-número de reversões, número de vezes no ano em que há mudança entre o tipo de taxa (ascensão e recessão), considerando o período contínuo.
- Estresse hídrico em plantas (níveis de queda)

- Aprisionamento de organismos em ilhas e planícies de inundação (níveis crescentes)

- Estresse dessecação de organismos de baixa mobilidade na beira do rio (zona variável)

Fonte: adaptado de TNC (2009) 
calculados para cada um dos 33 parâmetros, por ano hidrológico, no período pré-impacto. A categoria RVA baixa é representada pelos valores menores ou iguais ao percentil $33^{\circ}$, a categoria RVA média pelos valores na faixa do $34^{\circ}$ a $67^{\circ}$ percentil e na categoria RVA alta os valores acima do percentil $67^{\circ}$.

Dessa forma, o fator de alteração hidrológica (HA) é calculado para cada uma das três categorias de cada parâmetro, com base na frequência esperada (FE) com que os valores do período pós-impacto deveriam cair em cada categoria (igual a frequência do período pré-impacto) e na frequência com que eles realmente caíram (FO) em cada categoria, conforme Equação 1.

$\mathrm{HA}=(\mathrm{FO}-\mathrm{FE}) / \mathrm{FE}$

Onde:

$H A=$ fator de alteração hidrológica, podendo ser apresentado em porcentagem, multiplicando-o por cem;

$F E=$ frequência esperada, que é o número de valores na categoria durante o período pré-impacto multiplicado pela razão entre o número de anos do período pós-impacto e o número de anos do pré-impacto. Para a análise não paramétrica esse valor deveria ser igual para as três categorias $(33,33 \%$ do número de anos do período pós-impacto), porém os valores anuais coincidentes com os valores dos limites entre as categorias são todos colocados na categoria intermediária, podendo acarretar em uma distribuição não uniforme entre as categorias;

$F O=$ frequência observada, que é o número de vezes (anos) em que os valores dos parâmetros IHA caíram em cada categoria no período pós-impacto.

Os valores positivos do fator de alteração hidrológica significam que a frequência de valores na categoria aumentou do período pré-impacto para o período pós-impacto, enquanto que os valores negativos significam que a frequência de valores diminuiu (TNC, 2009).

\section{RESULTADOS}

Foi identificada, através do teste de hipótese não paramétrico de Pettitt, a ruptura da homogeneidade da série de vazões no ano de 1977 no rio Atibaia (posto 3D-006) e 1984 nos rios Jaguari (posto 3D-009) e Piracicaba (posto 4D-007), próximas ao início da operação dos reservatórios do Sistema Cantareira, sendo verificada uma diminuição na média das vazões desses três postos, a partir dessa ruptura, passando de 30,01 para 22,92 $\mathrm{m}^{3} / \mathrm{s}$ no rio Atibaia, de 34,58 para $17,44 \mathrm{~m}^{3} / \mathrm{s}$ no rio Jaguari e de 148,84 para $127,33 \mathrm{~m}^{3} / \mathrm{s}$ no rio Piracicaba.

Já no rio Camanducaia, verificou-se a ruptura da homogeneidade no ano de 1975 e, diferentemente dos demais rios, houve um aumento na média das vazões, passando de 12,86 para 15,61 m³ $/ \mathrm{s}$.

Nas análises da série de vazões do rio Atibaia, após o ano de 1977, considerado como o período pós-impacto, observa-se através da Figura 2, que houve um aumento na frequência das vazões mensais menores (abaixo do $33^{\circ}$ percentil - categoria RVA baixa), em todos os meses do ano, assim como das vazões mínimas anuais de 1 a 90 dias, refletindo em um aumento na contagem das vazões consideradas como pulso baixo (abaixo de $17 \mathrm{~m}^{3} / \mathrm{s}$ ) e na mediana da sua duração (de 3 para 6 dias), representados pelo aumento na categoria RVA alta (acima do $67^{\circ}$ percentil) desses parâmetros.

Conforme Figura 3, a mediana das vazões mínimas de 7 dias diminuiu aproximadamente $25 \%$, passando de 11,7 para $8,9 \mathrm{~m}^{3} / \mathrm{s}$.

Também para as vazões máximas anuais, houve uma diminuição na frequência dos valores maiores (acima do

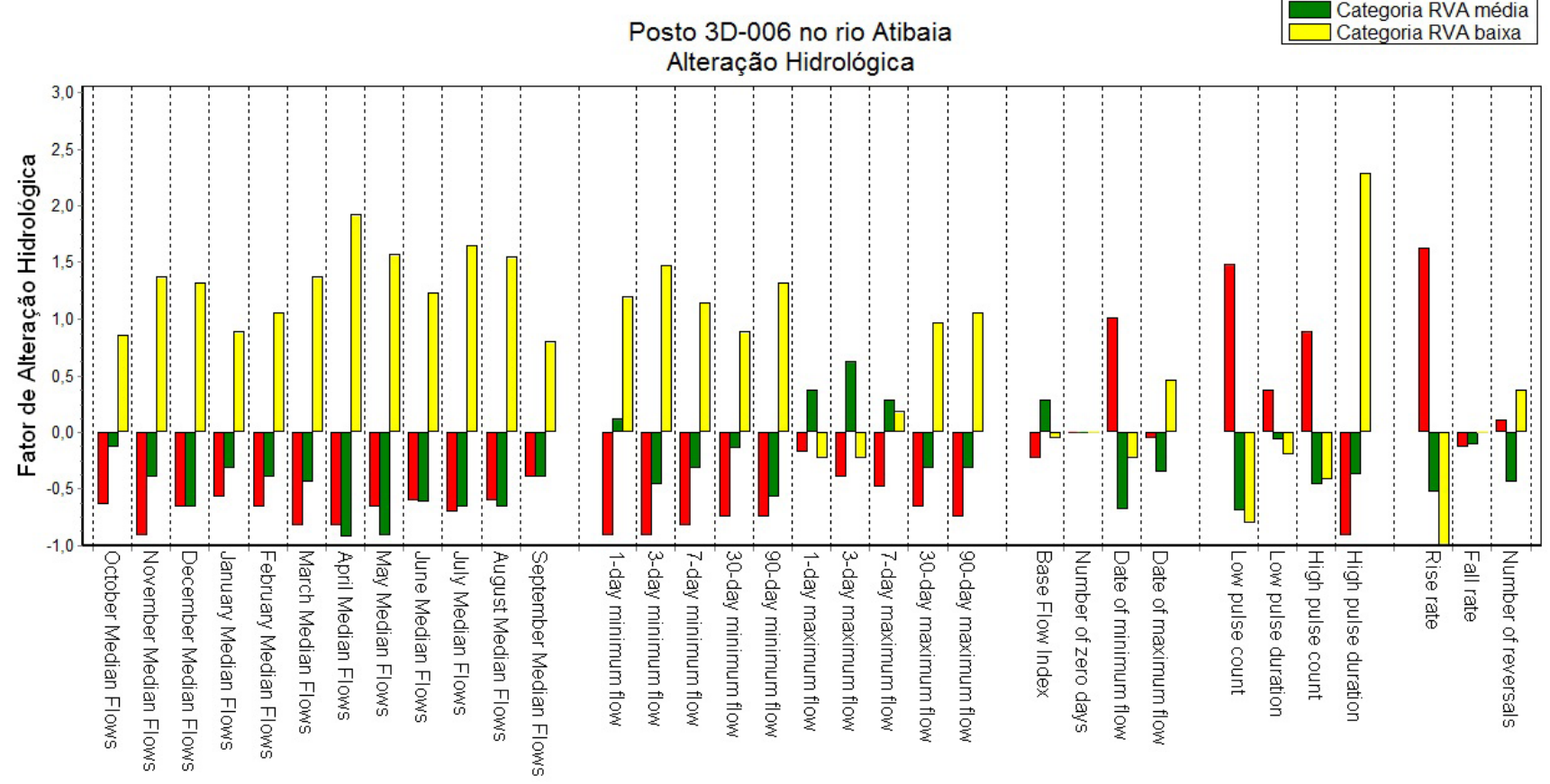

Figura 2. Fatores de Alteração Hidrológica do posto 3D-006 no rio Atibaia. 

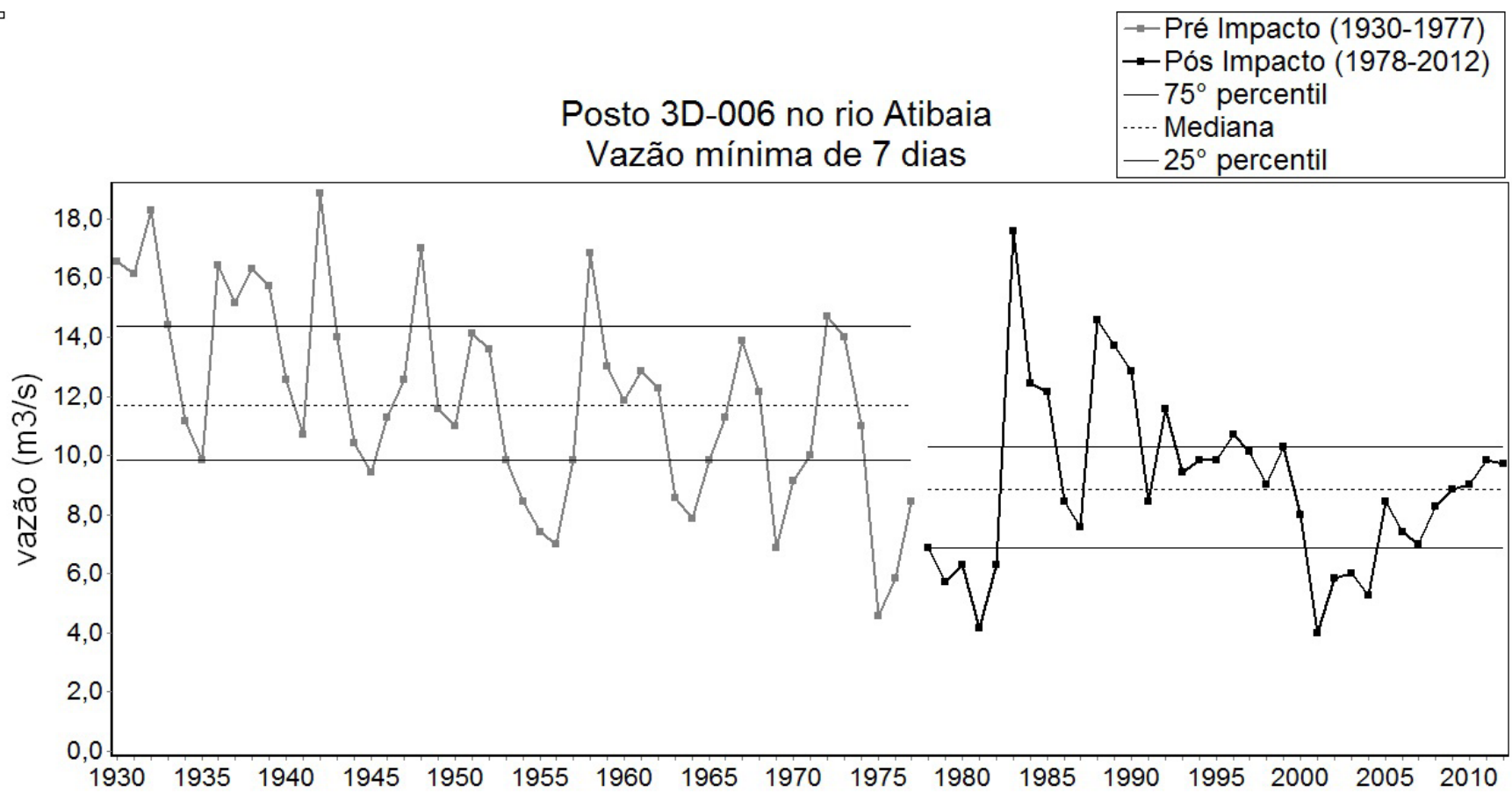

Figura 3. Vazões mínimas anuais de 7 dias consecutivos do posto 3D-006 no rio Atibaia.

$67^{\circ}$ percentil - categoria RVA alta), principalmente nas de maior duração (30 e 90 dias, passando a mediana dessas vazões de 59,7 para $47 \mathrm{~m}^{3} / \mathrm{s}$ e de 49,3 para $33,2 \mathrm{~m}^{3} / \mathrm{s}$, respectivamente), e, apesar do aumento na contagem das vazões consideradas como pulso alto (acima de $36 \mathrm{~m}^{3} / \mathrm{s}$ ), representado pelo aumento na categoria RVA alta, houve uma redução na mediana da duração dessas vazões, de 6 para 3 dias.

Em relação ao tempo de ocorrência das vazões extremas, para a vazão mínima anual houve um retardo de quase um mês, já que a mediana de ocorrência dessas vazões no período pré-impacto era no dia juliano 271 (28 de setembro) e no período pós-impacto passou para o dia 297 (24 de outubro). Já para a vazão máxima anual houve uma pequena antecipação do dia 35 (04 de fevereiro) para o dia 28 (28 de janeiro).

A diminuição nas vazões pode ser constatada também pela mudança na curva de permanência das vazões (Figura 4).

A partir do ano de 1984, no rio Jaguari, conforme Figura 5, pode-se observar também o aumento na frequência dos valores mais baixos das vazões (categoria RVA baixa), como nas vazões mensais, em todos os meses do ano, e nas vazões mínimas e máximas anuais, além do aumento na contagem das vazões consideradas como pulso baixo (abaixo de $18 \mathrm{~m}^{3} / \mathrm{s}$ ), representado pelo aumento na categoria RVA alta, apesar da diminuição na mediana das durações dessas vazões (passando de 8 para 6 dias), assim como a diminuição na contagem das vazões consideradas como pulso alto (acima de $42 \mathrm{~m}^{3} / \mathrm{s}$ ), representada pelo aumento na categoria RVA baixa (valores menores - abaixo do $33^{\circ}$ percentil) e na mediana das suas durações (passando de 5 para 2 dias).

Os maiores valores das vazões mensais do período seco (abril a setembro) e das vazões mínimas anuais (constantes nas categorias RVA média e alta), praticamente não foram mais registrados no período pós-impacto (fator de alteração hidrológica próximo ou igual a “ -1 ”), sendo que, conforme Figura 6, houve uma diminuição de aproximadamente $56 \%$ na mediana das vazões mínimas anuais de 7 dias consecutivos (de 11,7 para $5,1 \mathrm{~m}^{3} / \mathrm{s}$ ).

As vazões máximas de maior duração, de 30 e 90 dias, também sofreram uma diminuição na mediana em aproximadamente $50 \%$, passando de 76,5 para $39,5 \mathrm{~m}^{3} / \mathrm{s}$ e de 58,8 para $29,2 \mathrm{~m}^{3} / \mathrm{s}$, respectivamente.

A mediana da ocorrência das vazões extremas passou do dia juliano 276 (3 de outubro) para 291 (18 de outubro), em relação a vazão mínima anual, e de 30 (30 de janeiro) para 47 (16 de fevereiro), em relação a vazão máxima anual.

A diminuição nas vazões também pode ser verificada pela mudança ocorrida na curva de permanência das vazões (Figura 7).

Para o posto no rio Piracicaba, após o ano de 1984, conforme Figura 8, observa-se uma diminuição nas vazões mensais, principalmente no período seco (abril a setembro), representada pelo aumento dos valores da categoria RVA baixa e diminuição das categorias média e alta na maioria dos meses, e nas vazões mínimas anuais, sendo que, conforme Figura 9, a mediana das vazões mínimas de 7 dias diminuiu aproximadamente 15\%, passando de 45,57 para $38,5 \mathrm{~m}^{3} / \mathrm{s}$.

Já as vazões máximas anuais de menor duração, de 1 e 3 dias, tiveram um aumento na mediana dos valores de 618 para $644 \mathrm{~m}^{3} / \mathrm{s}$ e de 540,7 para $589 \mathrm{~m}^{3} / \mathrm{s}$, respectivamente, e uma diminuição no valor da mediana das vazões máximas anuais de 7, 30 e 90 dias, de 488,6 para $478,4 \mathrm{~m}^{3} / \mathrm{s}$, de 359,1 para $307,5 \mathrm{~m}^{3} / \mathrm{s}$ e de 281,5 para $232 \mathrm{~m}^{3} / \mathrm{s}$, respectivamente.

Pode-se notar também uma diminuição nos registros de vazões consideradas como pulso baixo (abaixo de $72 \mathrm{~m}^{3} / \mathrm{s}$ ), representada pela diminuição dos valores na categoria RVA alta, 
apesar do aumento na mediana das durações dessas vazões de 2 para 5 dias, e o aumento nos registros das vazões consideradas como pulso alto (acima de $181 \mathrm{~m}^{3} / \mathrm{s}$ ), representado pelo aumento na categoria RVA alta, apesar da diminuição na mediana das durações de 5 para 3 dias.

Em relação à data de ocorrência das vazões extremas, praticamente não houve alteração na mediana desses valores em relação a vazão mínima anual, ficando em torno dos dias julianos 274 e 275 (1 e 2 de outubro). Já para a vazão máxima anual a mediana se alterou do dia 27 (27 de janeiro) para o dia 47 (16 de fevereiro).

Na Figura 10 observa-se uma leve alteração em relação à diminuição da permanência das vazões.

No rio Camanducaia, o qual não sofre influência direta dos reservatórios do Sistema Cantareira, nem foi identificada substancial interferência antrópica nesse curso d'água, observa-se

Figura 4. Curvas de permanência das vazões do posto 3D-006 no rio Atibaia.

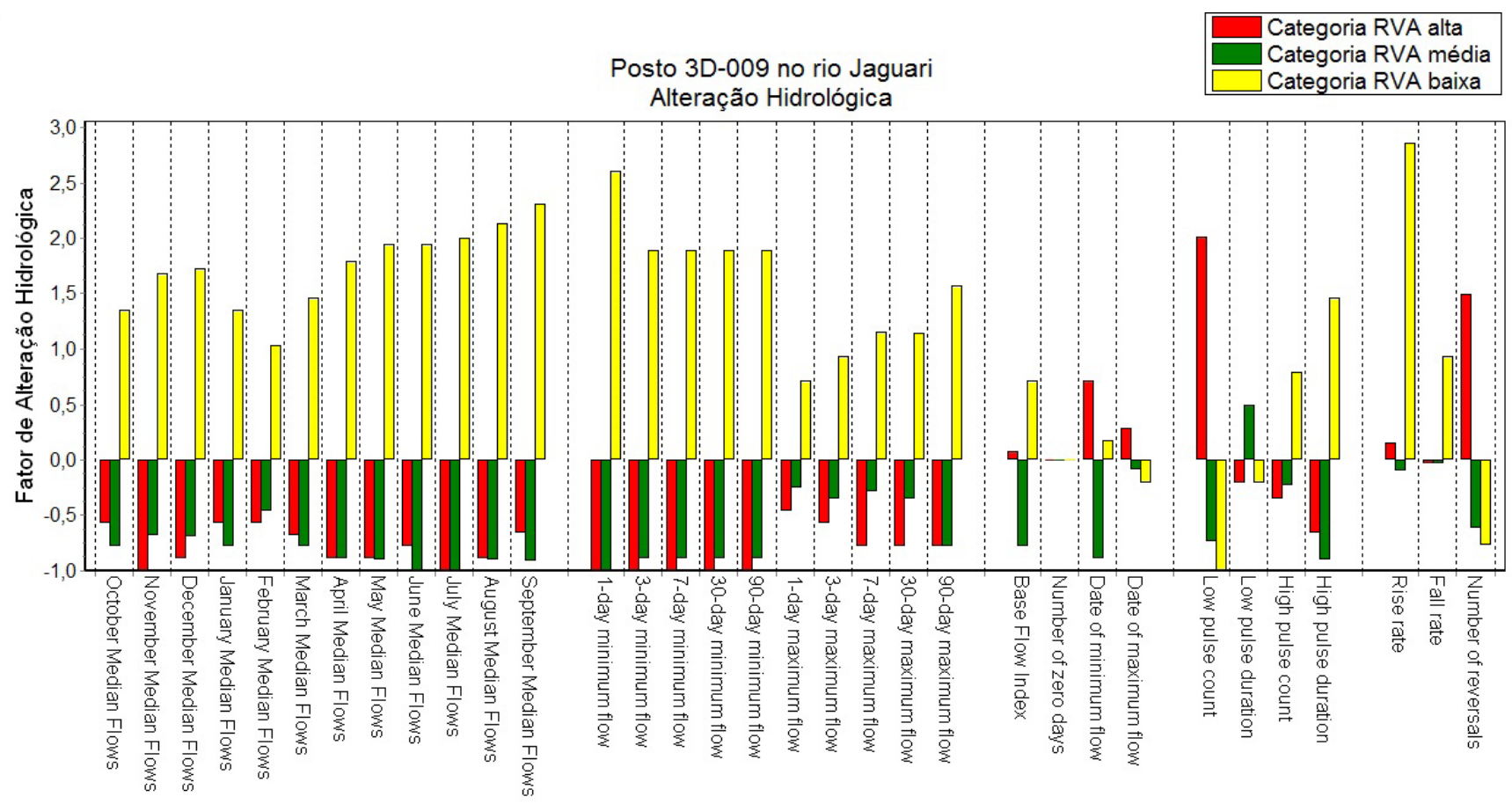

Figura 5. Fatores de Alteração Hidrológica do posto 3D-009 no rio Jaguari. 
na Figura 11, que diferentemente dos demais postos analisados, os quais apresentaram aumento na frequência de registros das vazões mensais menores (categoria RVA baixa), a partir do ano de 1975, houve aumento nas vazões mensais maiores (categoria RVA alta).

Em relação às vazões mínimas anuais de 7 dias, houve um aumento na frequência das vazões nas categorias RVA alta e baixa e diminuição na categoria média, no entanto, o valor da mediana dessas vazões se manteve em $4 \mathrm{~m}^{3}$ /s (Figura 12).

Já para as vazões máximas anuais, houve um aumento na mediana de todas essas vazões, sendo que para as de durações de 30 e 90 dias, a mediana passou de 31,22 para $35,6 \mathrm{~m}^{3} / \mathrm{s}$ e de 24,04 para $27,19 \mathrm{~m}^{3} / \mathrm{s}$, respectivamente.

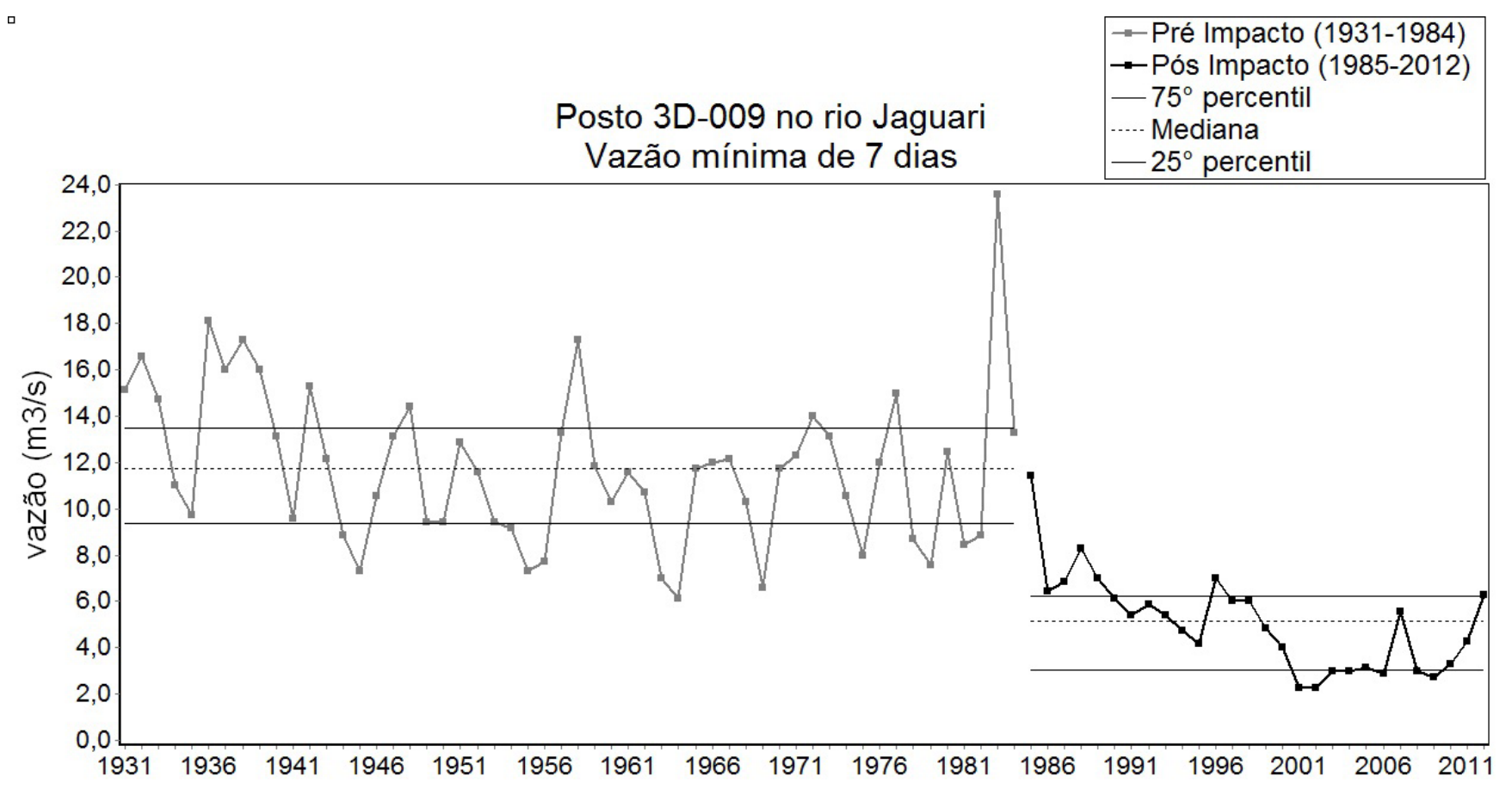

Figura 6. Vazões mínimas anuais de 7 dias consecutivos do posto 3D-009 no rio Jaguari.

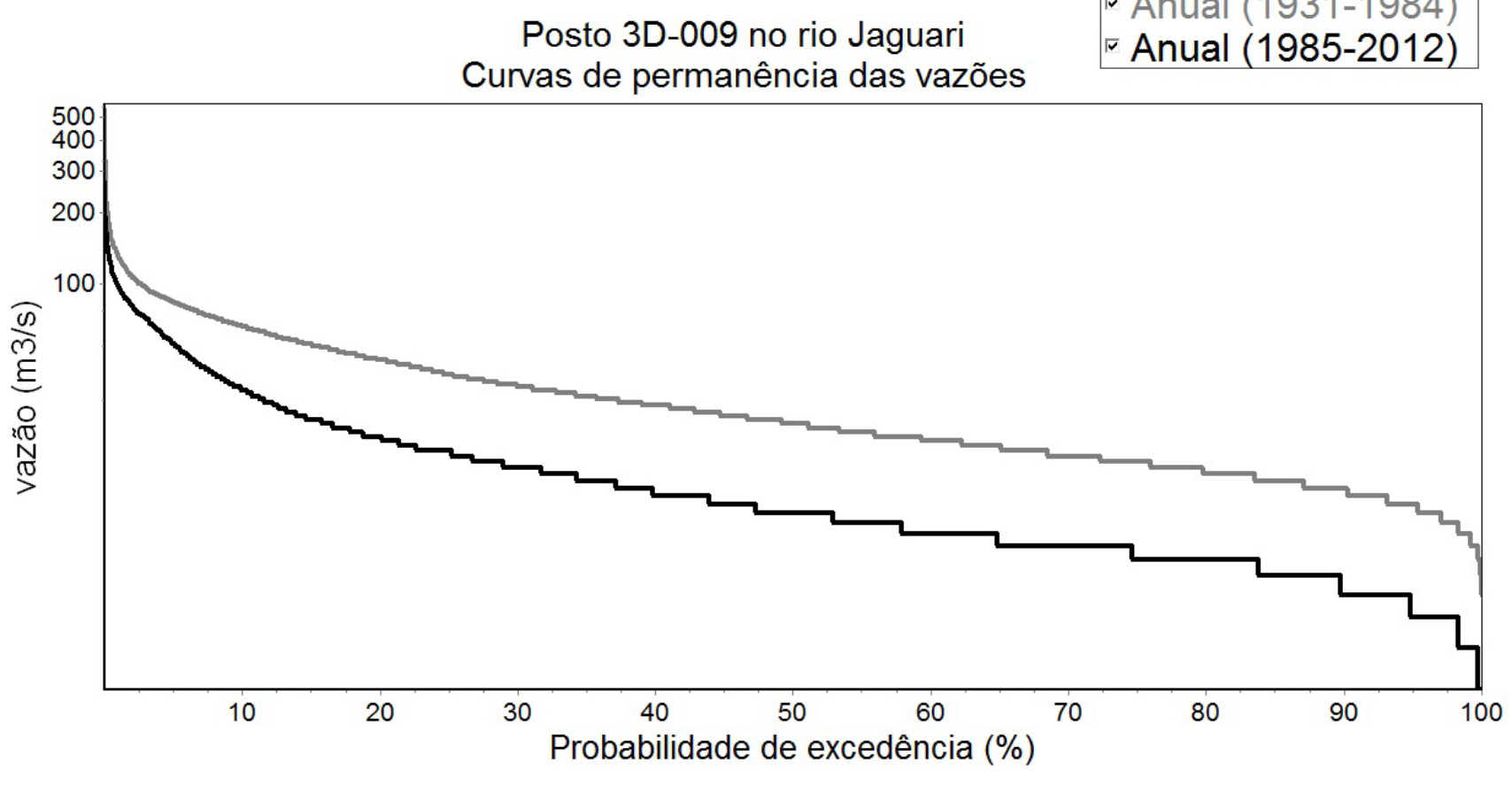

Figura 7. Curvas de permanência das vazões do posto 3D-009 no rio Jaguari. 
Nota-se também que em relação às vazões consideradas como pulso baixo (abaixo de $6 \mathrm{~m}^{3} / \mathrm{s}$ ) houve uma pequena diminuição nos registros dessas vazões, representada pela diminuição na categoria RVA alta, e a mediana das durações passou de 6 para 4 dias. Já para os pulsos altos (acima de $15 \mathrm{~m}^{3} / \mathrm{s}$ ) houve um aumento no registro dessas vazões, representado pelo aumento na categoria RVA alta, mas não houve alteração na mediana das durações, ficando em 3 dias.
Nas datas de ocorrência das vazões extremas não houve praticamente alterações em relação à mediana, se mantendo nos dias julianos 26 e 25 (26 e 25 de janeiro) para a vazão máxima anual e em 276 e 280 ( 3 e 7 de outubro) para a vazão mínima anual.

Conforme Figura 13, observa-se um pequeno aumento na permanência das vazões desse rio.

As alterações verificadas para o rio Camanducaia, através dos parâmetros calculados, não foram tão significativas quanto nos

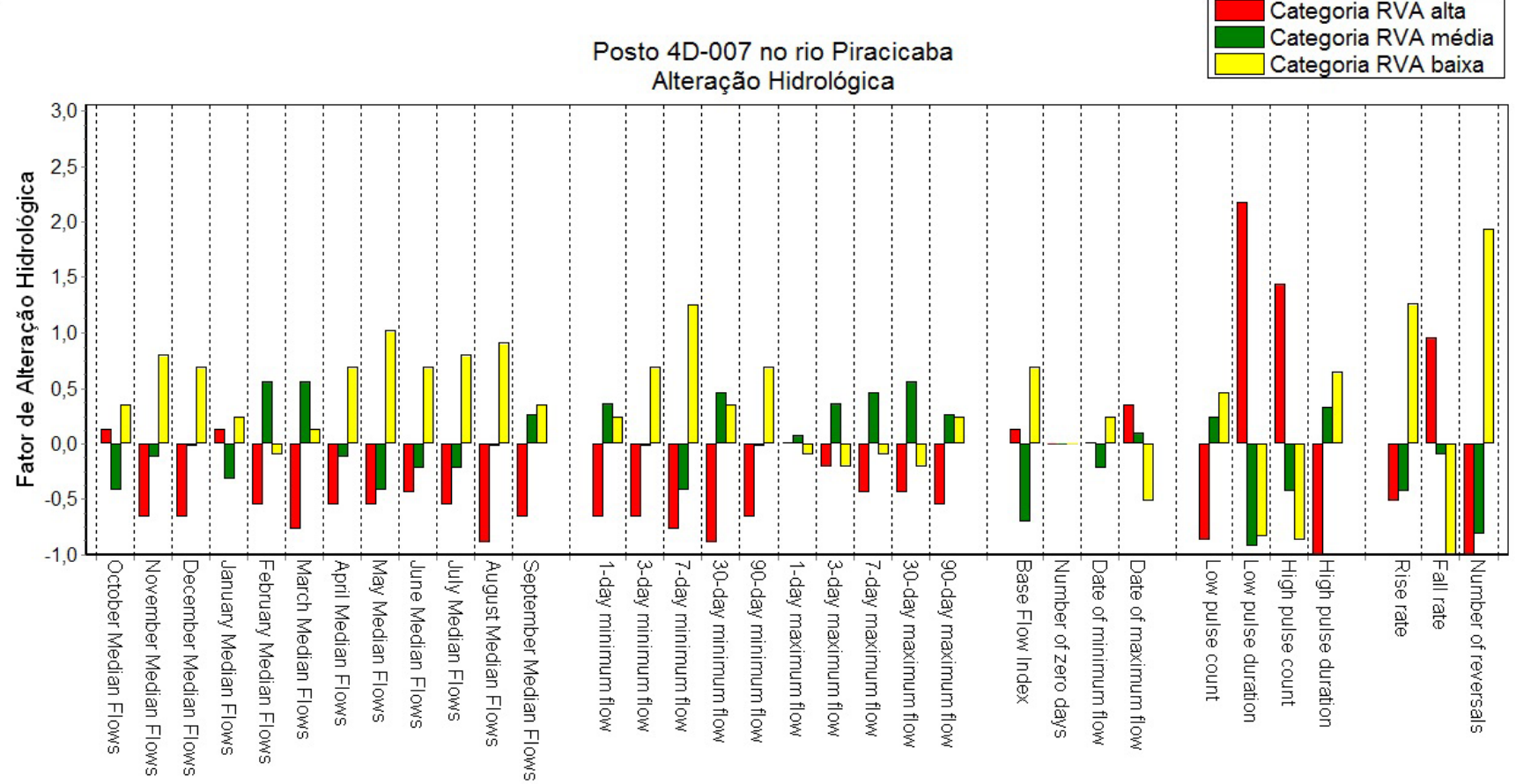

Figura 8. Fatores de Alteração Hidrológica do posto 4D-007 no rio Piracicaba.

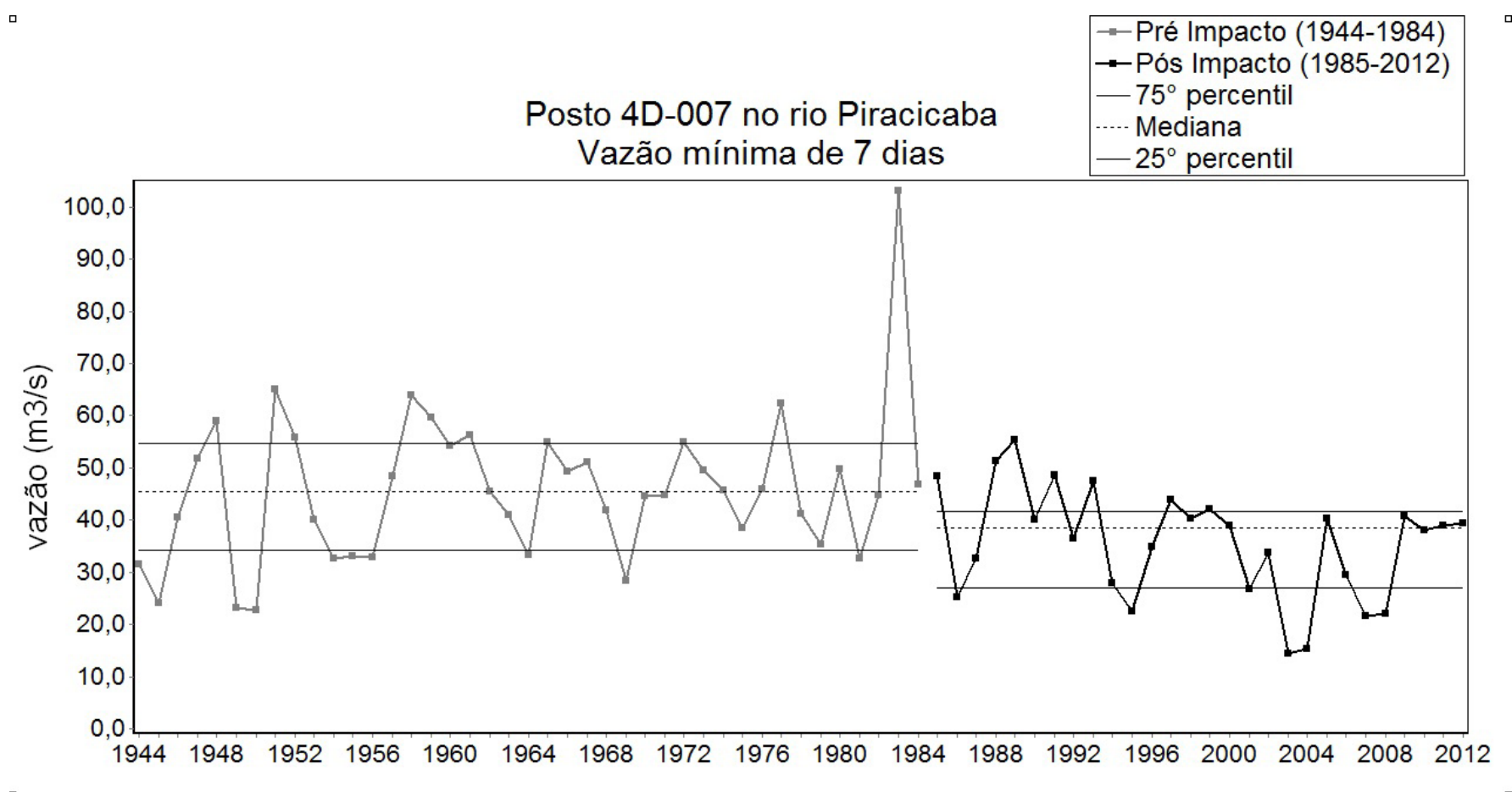

Figura 9. Vazões mínimas anuais de 7 dias consecutivos do posto 4D-007 no rio Piracicaba. 


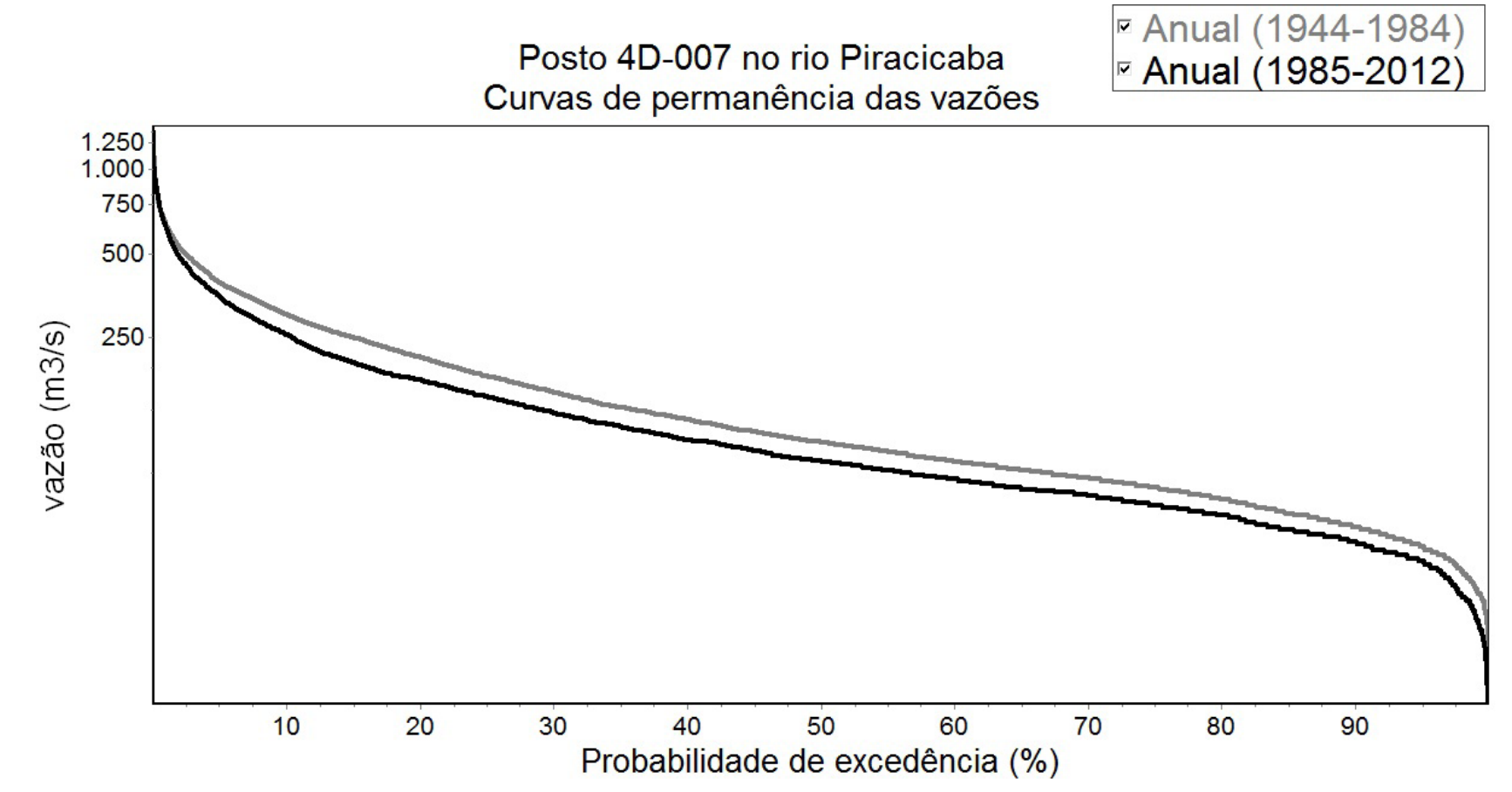

Figura 10. Curvas de permanência das vazões do posto 4D-007 no rio Piracicaba.

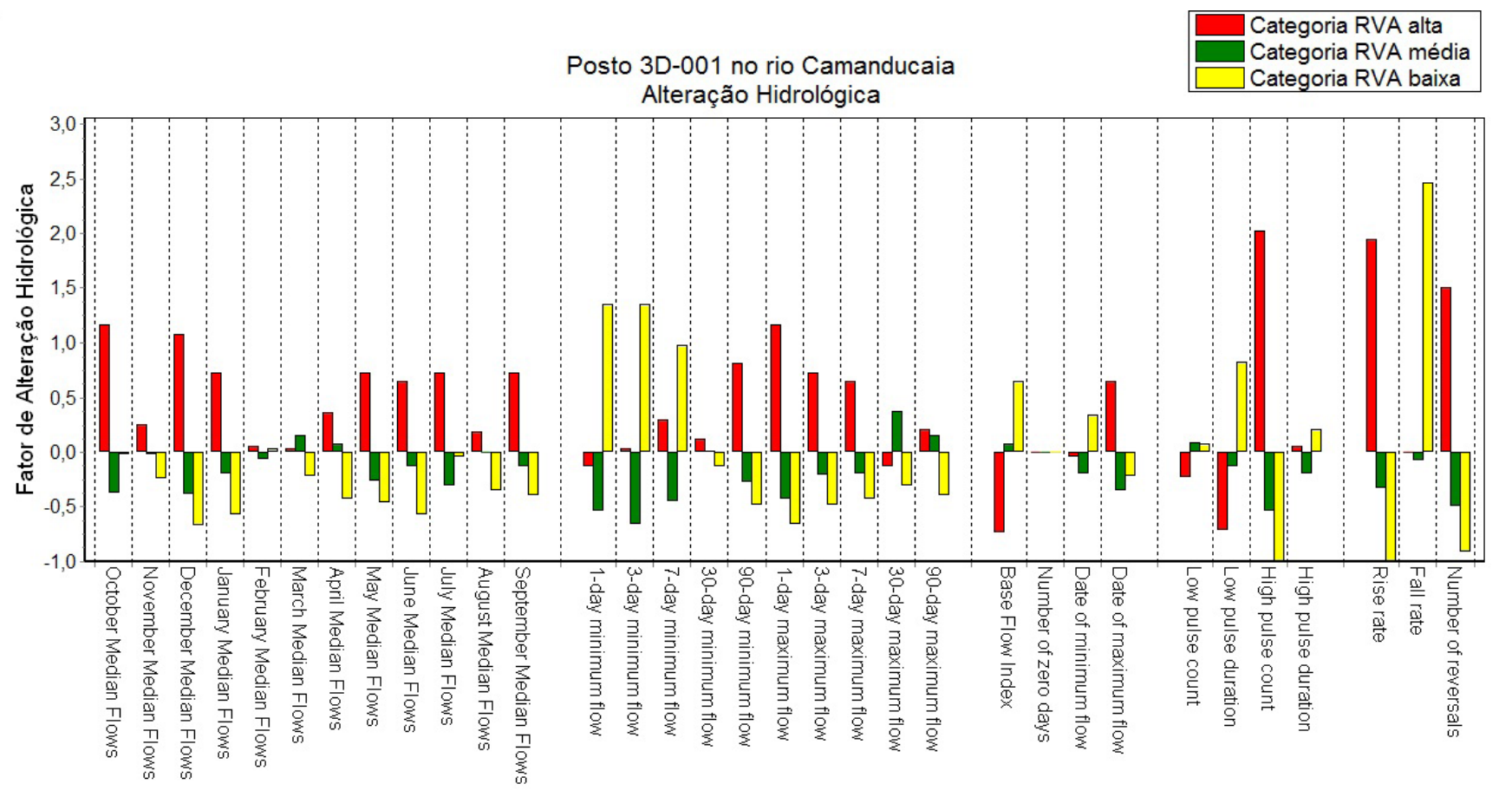

Figura 11. Fatores de Alteração Hidrológica do posto 3D-001 no rio Camanducaia.

demais rios da bacia, e apresentaram comportamento diferente dos demais rios.

As tabelas com os valores dos fatores de alteração hidrológica de cada categoria RVA, valores dos limites entre essas categorias, valores mínimos, máximos e da mediana de cada parâmetro hidrológico, nos períodos pré e pós-impacto, para cada posto analisado, estão anexadas no trabalho de Frederice (2014).

\section{DISCUSSÃO}

Em relação à caracterização da precipitação na bacia do rio Piracicaba, importante parâmetro do ciclo hidrológico relacionado ao regime de vazões, as séries temporais de alguns postos pluviométricos da bacia foram testadas por Groppo et al. (2001), para o período de 1947 a 1997, que concluíram que as 


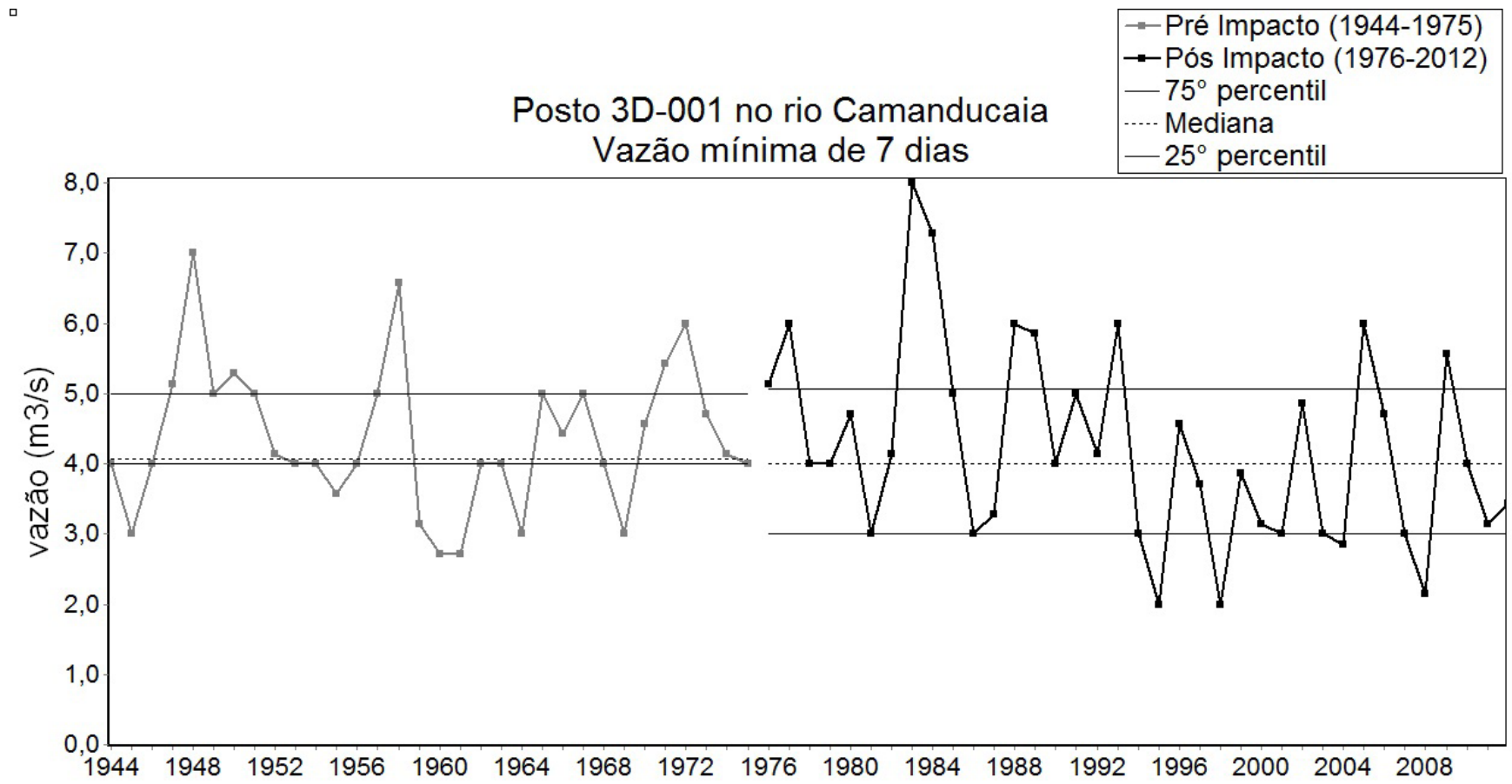

Figura 12. Vazões mínimas anuais de 7 dias consecutivos do posto 3D-001 no rio Camanducaia.

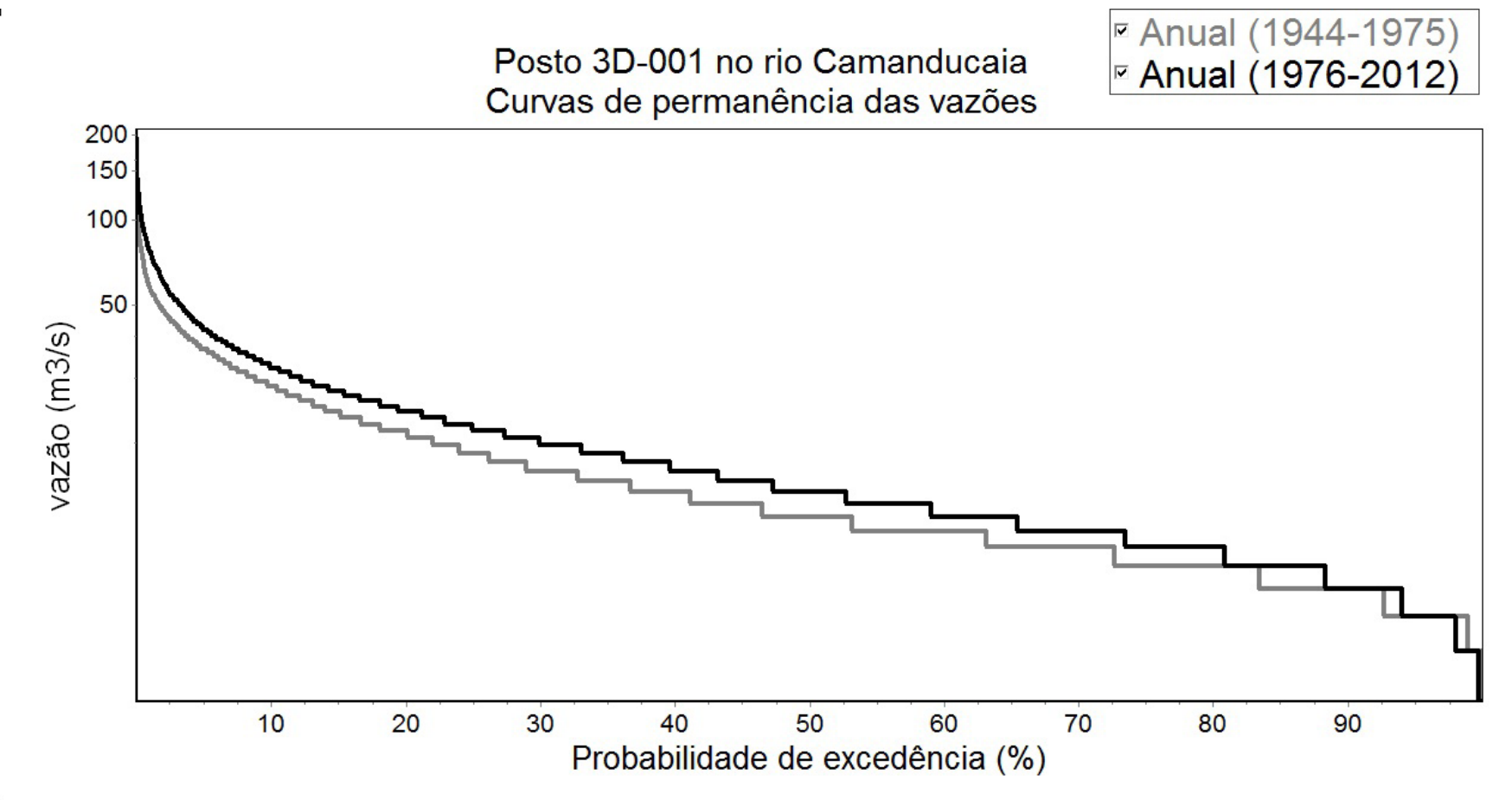

Figura 13. Curvas de permanência das vazões do posto 3D-001 no rio Camanducaia.

precipitações apresentaram tendências positivas estatisticamente significativas em praticamente toda bacia. Já Moraes et al. (1997), que estudaram as séries de precipitação na bacia em um período maior, de 1930 a 1995, não notaram uma variação brusca nas séries, mas de modo geral, uma tendência positiva, porém não estatisticamente significativa no período.

Neste trabalho, conforme consta na Tabela 3, verificou-se que após a constatação da ruptura da homogeneidade das séries de vazões médias diárias, houve um decréscimo na média aritmética das vazões em aproximadamente $24 \%$ no rio Atibaia, $50 \%$ no rio Jaguari e $14 \%$ no rio Piracicaba, contrário ao rio Camanducaia, em que houve um aumento de $21 \%$.

Estes resultados estão coerentes com o trabalho de Groppo et al. (2001), que testaram as séries de vazões médias anuais dos rios Atibaia, Jaguari, Piracicaba e Camanducaia, no período de 1947 a 1996, e verificaram tendência negativas nas vazões dos 
Tabela 3. Mudança na média aritmética das vazões, após a constatação da ruptura da homogeneidade.

\begin{tabular}{cllcccc}
\hline Posto & \multicolumn{1}{c}{ Rio } & Período & RUP & $\begin{array}{c}\text { Média pré } \\
\text { RUP } \\
\left(\mathbf{m}^{3} / \mathbf{s}\right)\end{array}$ & $\begin{array}{c}\text { Média pós } \\
\text { RUP } \\
\left(\mathbf{m}^{3} / \mathbf{s}\right)\end{array}$ & $\begin{array}{c}\text { MM } \\
(\mathbf{0})\end{array}$ \\
\hline 3D-001 & Camanducaia & $1944-2012$ & 1975 & 12,86 & 15.61 & +21 \\
3D-006 & Atibaia & $1930-2012$ & 1977 & 30,01 & 22,92 & -24 \\
3D-009 & Jaguari & $1931-2012$ & 1984 & 34,58 & 17,44 & -50 \\
4D-007 & Piracicaba & $1944-2012$ & 1984 & 148,84 & 127,33 & -14 \\
\hline
\end{tabular}

RUP: Ano em que foi detectada a ruptura da homogeneidade da série de vazões médias diária, por meio do teste de Pettitt. MM: Mudança na média.

rios influenciados pelo Sistema Cantareira, sendo essa tendência estatisticamente significativa para os rios Atibaia e Jaguari, e estatisticamente não significativa para o rio Piracicaba. Para o rio Camanducaia (na mesma bacia, porém sem influência do Sistema Cantareira), verificou-se tendência positiva estatisticamente não significativa nas vazões, acompanhando a tendência positiva da precipitação.

Em relação à qualidade das águas da bacia, Groppo et al. (2006) analisaram as tendências temporais dos parâmetros de qualidade da água nos rios Atibaia, Jaguari e Piracicaba, entre 1979 a 2001, contemplando praticamente apenas o período posterior à construção dos reservatórios do Sistema Cantareira. Nessa análise observou-se que, de maneira geral, houve uma degradação da qualidade da água, representada pelas tendências positivas nos parâmetros DBO, nitrogênio, fósforo total e cloreto, e negativas no parâmetro $\mathrm{OD}$, sugerindo que a causa mais provável da deterioração desses rios foi a diminuição significativa da vazão com a implantação do Sistema Cantareira e de expressivo crescimento populacional da bacia, acompanhado pelo lançamento de efluentes.

Complementar aos trabalhos citados e outros similares, que também analisaram as vazões dos rios influenciados pelo Sistema Cantareira e detectaram uma diminuição geral nas vazões desses rios, neste trabalho foram detalhadas e quantificadas essas alterações, através de 33 parâmetros hidrológicos, que caracterizam a magnitude, o tempo, a frequência, a duração e a taxa de flutuações das vazões, que segundo as relações teóricas abordadas na bibliografia, descritas na Tabela 2 , podem acarretar em mudanças nos processos ecológicos associados, como: as diminuições nas vazões podem influenciar na quantidade disponível de habitat na maior parte do tempo e na diversidade e número de organismos dos rios; as consideráveis diminuições nas vazões mínimas anuais podem ser estressantes para diversos organismos; as modificações na frequência e duração das cheias podem eliminar a desova, as indicações migratórias para os peixes, ou reduzir o acesso a zonas de reprodução e berçário; dentre outras (RICHTER et al., 1997).

No entanto, neste trabalho apenas chama-se atenção para as possíveis alterações dos processos ecológicos dos rios da bacia do Piracicaba e a degradação da qualidade das águas, relacionadas às alterações hidrológicas verificadas, devido à carência de dados sobre a qualidade das águas e os ecossistemas aquáticos existentes no período anterior ao represamento desses rios, sendo difícil a comprovação da relação na bacia estudada.

Outros trabalhos utilizaram as categorias RVA para identificar as alterações hidrológicas no regime natural de vazões, como Santos e Souza (2015) no Rio Paraná, concluindo que as variáveis que sofreram maior impacto, pelo efeito da cascata de reservatórios na bacia, foram às relacionadas a eventos extremos. Chen et al. (2010) identificou, na bacia hidrográfica do rio Dongjian, sul da China, alterações hidrológicas significativas causadas pela construção de barragens e potenciais ameaças a espécies de animais selvagens. $\mathrm{Na}$ bacia do rio Green em Washington (EUA), segundo Mathews e Richter (2007), o método IHA foi utilizado como parte de um projeto de desenvolvimento de indicadores ecológicos, devido à grande diminuição na abundância e distribuição de salmonídeos na bacia, após a barragem Howard Hanson, auxiliando no estabelecimento das relações entre os parâmetros hidrológicos e os ciclos de vida das espécies e no levantamento de hipóteses sobre como essas alterações poderiam estar afetando essas espécies e os processos ecológicos.

As alterações hidrológicas identificadas neste trabalho podem também servir de base para estudos ecológicos futuros, auxiliando na formulação de hipóteses sobre a relação dos ecossistemas específicos da bacia com o regime de vazões e os possíveis impactos ocorridos, além da identificação de fluxos importantes a serem mantidos para a preservação e restauração de importantes componentes desses ecossistemas e auxiliar em novos estudos para determinação de regras operativas do Sistema Cantareira, baseadas em vazões de referências sazonais que levem em consideração a variabilidade natural do regime de vazões.

Além dos impactos ecológicos, as alterações hidrológicas podem influenciar nos processos de outorga de direito de uso dos recursos hídricos da bacia, visto que conforme estabelecido pela Resolução ANA n 429/04 (ANA, 2004), a vazão máxima outorgável, nos cursos d'água situados a jusante do Sistema Cantareira, é de $50 \%$ da vazão mínima anual de 7 dias, associada ao período de retorno de 10 anos $\left(Q_{7,10}\right)$, e foi constatada uma diminuição da mediana da vazão mínima anual de 7 dias para os rios Atibaia (25\% no posto 3D-006), Jaguari (56\% no posto 3D-009) e Piracicaba (15\% no posto 4D-007), após a implantação desse sistema.

Nota-se através das curvas de permanência das vazões dos rios influenciados pelo Sistema Cantareira uma redução em quase todo espectro de vazões, sendo as curvas dos períodos pré e pós-impacto praticamente paralelas, não indicando regularização das vazões para a bacia do rio Piracicaba no período pós-impacto. Isso explica-se pelo fato das vazões regularizadas pelos reservatórios do Sistema Cantareira serem revertidas para a bacia do Alto Tietê.

Assim, observa-se uma diminuição na disponibilidade hídrica nesses cursos d'água, sendo que as vazões médias diminuíram cerca de $7 \mathrm{~m}^{3} / \mathrm{s}$ no rio Atibaia (influenciado pelos 
reservatórios Atibainha e Cachoeira que regularizam e revertem cerca de $9 \mathrm{~m}^{3} / \mathrm{s}$ ), $17 \mathrm{~m}^{3} / \mathrm{s}$ no rio Jaguari (influenciado pelos reservatórios Jaguari-Jacareí que regularizam e revertem cerca de $22 \mathrm{~m}^{3} / \mathrm{s}$ ) e $21 \mathrm{~m}^{3} / \mathrm{s}$ no rio Piracicaba (influenciado pelo sistema equivalente, que regulariza e reverte cerca de $31 \mathrm{~m}^{3} / \mathrm{s}$ ), o qual recebe a contribuição de outros importantes afluentes que não tem seu regime de vazões influenciados por reservatórios, como o rio Camanducaia, que teve um aumento na média das vazões de cerca de $3 \mathrm{~m}^{3} / \mathrm{s}$.

Essas alterações poderiam ser ainda maiores, já que segundo a bibliografia consultada observou-se um aumento da precipitação na região, chamando atenção para a necessidade do planejamento e gerenciamento futuro dos recursos hídricos da bacia levarem em consideração não só as alterações verificadas nas séries de vazões, mas também a possibilidade das precipitações voltarem a ser menores.

Diante disso, atribui-se a diminuição na disponibilidade hídrica dos rios Atibaia, Jaguari e Piracicaba principalmente à implantação do Sistema Cantareira, apesar de ser uma deficiência deste trabalho não considerar também as mudanças no uso e ocupação do solo da bacia e as captações outorgadas a jusante do sistema. Porém, as maiores demandas de água da bacia estão localizadas próximas a região metropolitana de Campinas, que fica a jusante dos postos fluviométricos selecionados nos rios Atibaia e Jaguari, os quais apresentaram maiores alterações no regime de vazões.

\section{CONCLUSÃO}

Para os rios influenciados pelo Sistema Cantareira foi constatado, para o período definido como pós-impacto, no geral, uma diminuição nas vazões médias, principalmente no período seco (abril a setembro), assim como a diminuição no valor das vazões mínimas e a diminuição na duração das vazões altas. Essas mudanças foram mais significativas no rio Jaguari, seguido pelo rio Atibaia, e foram menos significativas no rio Piracicaba, o qual encontra-se mais distante dos reservatórios.

Já para o rio Camanducaia (sem influência do Sistema Cantareira), após a década de 70, constatou-se, no geral, um aumento nas vazões médias, assim como o aumento na frequência de ocorrência das vazões altas. Porém, as mudanças ocorridas nesse rio não foram tão significativas, como nos demais.

Assim, e considerando que a ruptura na homogeneidade das séries de vazões, determinadas pelo teste de Pettitt, coincidiram com o histórico de construção dos reservatórios do Sistema Cantareira e que, de acordo com a bibliografia consultada, no período analisado houve um pequeno aumento nas precipitações da bacia, atribuiu-se as alterações ocorridas no regime fluvial dos rios Atibaia, Jaguari e Piracicaba principalmente à implantação e operação do Sistema Cantareira.

Acredita-se que essas alterações constatadas, principalmente nos rios Atibaia e Jaguari, podem ter impactado os seus ecossistemas fluviais, baseado nos conceitos abordados das relações dos processos ecológicos com os parâmetros hidrológicos. Porém, tal suposição é de difícil comprovação devido à carência de dados sobre os ecossistemas no período anterior à construção desses reservatórios.
Portanto, para novos estudos de implantação de grandes reservatórios em cursos d'água e transposição de água para outras bacias, recomenda-se que sejam estudadas as interações do regime hidrológico com os ecossistemas aquáticos associados e a qualidade da água, e que sejam considerados os prejuízos causados a essas interações, além de prever regras operativas baseadas em uma vazão sazonal (hidrograma), levando em consideração o regime hidrológico natural do rio, e não apenas em uma vazão mínima constante a ser mantida para jusante.

Esse torna-se um desafio aos sistemas de gestão atuais, devido à exigência de um grande número de dados e informações, para a descrição do intervalo de variabilidade das vazões necessárias para suportar um ecossistema fluvial saudável, aliados a um monitoramento contínuo capaz de fornecer respostas bióticas, o que demandaria também grandes esforços em termos de recursos financeiros e humanos.

A implantação de um sistema de gestão do Sistema Cantareira, considerando vazões sazonais a serem mantidas para jusante, baseadas na variabilidade natural do regime de vazões, é ainda mais complexa, devido à grande dependência das vazões regularizadas por esses reservatórios para abastecimento público das duas maiores regiões (em população e economia) do estado de São Paulo, além da ocupação das várzeas dos rios a jusante dos reservatórios, que impõe também restrições de descargas máximas de vazões.

No entanto, é necessário que se concentre esforços para a diminuição da dependência do abastecimento dessas regiões pelo Sistema Cantareira, de modo a permitir a inserção de algumas demandas do ecossistema na gestão desse manancial, e para que sejam realizados estudos ecológicos sobre as interações dos ecossistemas específicos da bacia com o regime de vazões, auxiliando na formulação de novas regras operativas.

\section{REFERÊNCIAS}

ADDINSOFT. XLSTAT: statistical analysis software. Versão 2014. New York: Addinsoft, 2014.

ANA - Agência Nacional de Águas. Resolução n 429, de 04 de agosto de 2004: delega competência e define os critérios e procedimentos para a outorga do direito de uso de recursos hídricos de domínio da União no âmbito das Bacias Hidrográficas dos Rios Piracicaba, Capivari e Jundiaí. Brasília: ANA, 2004. Disponível em: < http:// arquivos.ana.gov.br/resolucoes/2004/429-2004.pdf > . Acesso em: 07 ago. 2016.

ANA - Agência Nacional de Águas; DAEE - Departamento de Águas e Energia Elétrica. Nota Técnica Conjunta ANA/DAEE: Subsídios para a análise do pedido de outorga do Sistema Cantareira e para a definição das condições de operação dos seus reservatórios. Brasília: ANA, 2004. Disponível em: <http://arquivos.ana.gov. br/resolucoes/2004/428-RelatorioConjuntoCantareira.pdf $>$. Acesso em: 07 ago. 2016.

CHEN, Y. D.; YANG, T.; XU, C.; ZHANG, Q.; CHEN, X.; HAO, Z. Hydrologic alteration along the Middle and Upper East River 
(Dongiiang) basin, South China: a visually enhanced mining on the results of RVA method. Stochastic Environmental Research and Risk Assessment, v. 24, n. 1, p. 9-18, 2010. http://dx.doi.org/10.1007/ s00477-008-0294-7.

COBRAPE - Companhia Brasileira de Projetos e Empreendimentos. Plano das bacias hidrográficas dos Rios Piracicaba, Capivari e Jundiai 2010 a 2020: relatório final. São Paulo: Cobrape, 2011.

COLLISCHONN, W.; AGRA, S. G.; FREITAS, G. K.; PRIANTE, G. R.; TASSI, R.; SOUZA, C. F. Em busca do hidrograma ecológico. In: SIMPÓSIO BRASILEIRO DE RECURSOS HÍDRICOS, 16, 2005, João Pessoa. Anais... João Pessoa: ABRH, 2005. Disponível em: <http://www.lume.ufrgs.br/bitstream/ handle $/ 10183 / 17271 / 000504462$.pdf? sequence $=1>$. Acesso em: 12 jan. 2013.

FREDERICE, A. Análise do impacto do Sistema Cantareira sobre o regime de vaz̃ões na bacia do rio Piracicaba. 2014. 110 f. Dissertação (Mestrado em Hidráulica e Saneamento) - Escola de Engenharia de São Carlos, Universidade de São Paulo, São Carlos, 2014.

GROPPO, J. D.; GUAMERO, M. E.; MILDE, L. C. E.; MORAES, J. M.; MARTINELLI, L. A. Análise de séries temporais de vazão e de precipitação na bacia do Rio Piracicaba. Revista de Ciência \& Tecnologia, v. 8, n. 18, p. 109-117, 2001.

GROPPO, J. D.; MORAES, J. M.; GENOVEZ, A. M.; MARTINELLI, L. A. Estudo de tendência de parâmetros de qualidade de água na bacia do Rio Piracicaba. RBRH: Revista Brasileira de Recursos Hídricos, v. 11, n. 3, p. 79-87, 2006.

IRRIGART - Engenharia e Consultoria em Recursos Hídricos e Meio Ambiente Ltda. Bacias dos Rios Piracicaba, Capivari e Jundiaí: situação dos Recursos Hídricos 2002/2003: relatório síntese. Piracicaba: Irrigart, 2004.

MATHEWS, R.; RICHTER, B. D. Application of the indicators of hydrologic alteration software in environmental flow setting. Journal of the American Water Resources Association, v. 43, n. 6, p. 14001413, 2007. http://dx.doi.org/10.1111/j.1752-1688.2007.00099.x.
MORAES, J. M.; BALLESTER, M.V.; GENOVEZ, A.M.; KRUSH, A. V.; MARTINELLI, L. A.; MORTATTI, J.; VICTORIA, R. L. Análise de intervenção das séries temporais de vazão dos principais rios da bacia do Rio Piracicaba. RBRH: Revista Brasileira de Recursos Hídricos, v. 2, n. 2, p. 65-79, 1997.

PETTIT'T, A. N. A non-parametric approach to the change-point problem. Applied Statistics, v. 28, n. 2, p. 126-135, 1979. http:// dx.doi.org/10.2307/2346729.

RICHTER, B. D.; BAUMGARTNER, J. V.; POWELL, J.; BRAUN, D. P. A method for assessing hydrologic alteration within Ecosystem. Conservation Biology, v. 10, n. 4, p. 1163-1174, 1996. http://dx.doi. org/10.1046/j.1523-1739.1996.10041163.x.

RICHTER, B. D.; BAUMGARTNER, J. V.; WIGINGTON, R.; BRAUN, D. P. How much water does a river need? Freshwater Biology, v. 37, n. 1, p. 231-249, 1997. http://dx.doi.org/10.1046/j.13652427.1997.00153.x.

SANTOS, C. P.; SOUZA, C. F. Efeitos da cascata de reservatórios sobre a variabilidade natural de vazões: o caso do rio Paraná em Porto Primavera. RBRH: Revista Brasileira de Recursos Hídricos, v. 20, n. 3, p. 698-707, 2015.

TNC - The Nature Conservancy. Indicators of bydrologic alteration: version 7.1: user's manual. Virginia: TNC, 2009.

WHATELY, M.; CUNHA, P. Cantareira 2006: um olhar sobre o maior manancial de água da Região Metropolitana de São Paulo. São Paulo: Instituto Socioambiental, 2007.

\section{Contribuição dos autores}

Aline Frederice: Pesquisa bibliográfica, coleta e tratamento dos dados, análise e discussão dos resultados e elaboração do texto.

João Luiz Boccia Brandão: Orientação do estudo, discussão dos resultados e revisão do texto. 